DOI: $10.15393 /$ j3.art.2020.8030

UDC 517.44, 517.51, 517.58

L. MATEJÍČKA

\title{
A SOLUTION TO FOURTH QI'S CONJECTURE ON A COMPLETE MONOTONICITY
}

\begin{abstract}
In the paper, a complete monotonicity for some function is proved. This problem was posted by F. Qi and R.P. Agarwal as the fourth open problem of the collection of eight unsolved problems.
\end{abstract}

Key words: Laplace transform, Completely monotonic functions, Inequality

2010 Mathematical Subject Classification: 33B99, 44A10, 26A48, 26D07

1. Introduction. First, recall some useful definitions and theorems. The function $\psi(x)=d \ln \Gamma(x) / d x$ is called the digamma function, where $\Gamma(x)$ is the classical Euler's Gamma function [4]. For additional information on this function, please refer to [4] and the closely related references therein.

A function $f$ is said to be completely monotonic on the interval $I$, if $f(x)$ has derivatives of all orders on $I$ and the inequality $(-1)^{n} f^{(n)}(x) \geqslant 0$ holds for $x \in I$ and $n \in \mathbb{N}_{0}$. A characterization of a completely monotonic function is given by the Bernstein-Widder theorem [5], [6]. It reads: a function $f(x)$ on $(0, \infty)$ is completely monotonic if and only if there exists a bounded and non-decreasing function $\alpha(t)$, such that the integral

$$
f(x)=\int_{0}^{\infty} e^{-x t} d \alpha(t)
$$

converges for $x \in(0, \infty)$.

Let $f(x)$ be completely monotonic on $(0, \infty)$ and $f(\infty)=\lim _{x \rightarrow \infty} f(x) \geqslant 0$. Recall from the papers [2], [4] the following definition. Assume that the function $x^{r}(f(x)-f(\infty))$ is completely monotonic on $(0, \infty)$ for some (c) Petrozavodsk State University, 2020 
$r \in R$, while the function $x^{r+\varepsilon}(f(x)-f(\infty))$ is not (for any positive number $\varepsilon$ ); then the number $r$ is called the completely monotonic degree of $f(x)$ with respect to $x \in(0, \infty)$. The notation $\operatorname{deg}_{c m}^{x}[f(x)]$ denotes the completely monotonic degree $r$ of $f(x)$ with respect to $x \in(0, \infty)[4]$.

In the paper [4], F. Qi and R. P. Agarwal posed eight open problems on complete monotonicity. The seventh open problem was solved by Matejička in [3]. The fourth open problem says:

Open problem 1 Motivated by the results in [1], we guess that the difference between the right-hand and the left-hand sides of (2.5) (see [4, p. 6]) is a completely monotonic function on $(0, \infty)$.

Note that the left-hand side function $h(x)$ is given by

$$
\begin{aligned}
\Delta(x)= & \left(\psi^{\prime}(x)\right)^{2}+\psi^{\prime \prime}(x)>h(x)=\frac{1}{2 x^{4}}-\frac{1}{x^{3}}+\frac{34}{15 x^{2}}-\frac{14}{3 x}+\frac{14}{3(x+1)}+ \\
& +\frac{12}{5(x+1)^{2}}+\frac{17}{15(x+1)^{3}}+\frac{9}{20(x+1)^{4}}+\frac{1}{10(x+1)^{5}}- \\
& -\frac{7}{180(x+1)^{6}}-\frac{1}{30(x+1)^{7}}-\frac{1}{90(x+1)^{8}}+\frac{1}{900(x+1)^{10}}
\end{aligned}
$$

for $x>0$, and the right-hand side function $g(x)$ is given by

$$
\begin{aligned}
\Delta(x)=\left(\psi^{\prime}(x)\right)^{2} & +\psi^{\prime \prime}(x)<g(x)=\frac{1}{x^{4}}-\frac{1}{x^{3}}+\frac{7}{3 x^{2}}-\frac{5}{x+1}+\frac{8}{3(x+1)^{2}}+ \\
& +\frac{4}{3(x+1)^{3}}+\frac{7}{12(x+1)^{4}}+\frac{1}{6(x+1)^{5}}+\frac{1}{36(x+1)^{6}}
\end{aligned}
$$

for $x>0$.

In this paper, we often use the well-known Laplace-transform formulas

$$
\begin{aligned}
\frac{m !}{x^{m+1}} & =\int_{0}^{\infty} t^{m} e^{-x t} d t \quad \text { for } \quad x>0, \quad m \in \mathbb{N}_{0}, \\
\frac{m !}{(x+1)^{m+1}} & =\int_{0}^{\infty} t^{m} e^{-t} e^{-x t} d t \quad \text { for } \quad x>0, \quad m \in \mathbb{N}_{0} .
\end{aligned}
$$

The goal of the paper is to find a solution of the fourth Open problem 1. 


\section{Main Results.}

Theorem 1. Let $f(x)=g(x)-h(x)$ for $x>0$, where $h(x)$ and $g(x)$ are defined by (1) and (2), respectively. Then $f(x)$ is a strictly completely monotonic function on $(0, \infty)$.

Proof. Straightforward computation yields:

$$
\begin{aligned}
f(x)=\frac{1}{2 x^{4}}+\frac{1}{15 x^{2}}-\frac{1}{3 x}+\frac{1}{(x+1)}+ & \frac{4}{15(x+1)^{2}}+\frac{1}{5(x+1)^{3}}+ \\
+\frac{2}{15(x+1)^{4}}+\frac{1}{15(x+1)^{5}}+ & \frac{1}{15(x+1)^{6}}+\frac{1}{30(x+1)^{7}}+ \\
& +\frac{1}{90(x+1)^{8}}-\frac{1}{900(x+1)^{10}}
\end{aligned}
$$

for $x>0$.

Using the well-known formulas

$$
\frac{1}{x^{1+n}}=\int_{0}^{\infty} \frac{t^{n}}{n !} e^{-x t} d t, \quad \frac{1}{(x+1)^{1+n}}=\int_{0}^{\infty} \frac{t^{n}}{n !} e^{-(1+x) t} d t
$$

in (3), we get

$$
\begin{aligned}
f(x) & =\int_{0}^{\infty}\left[\frac{t^{3}}{12}+\frac{t}{15}-\frac{1}{3}+e^{-t}\left(\frac{1}{3}+\frac{4}{15} t+\frac{3}{10} t^{2}+\frac{2}{15 \cdot 3 !} t^{3}\right.\right. \\
& \left.\left.+\frac{1}{15 \cdot 4 !} t^{4}+\frac{1}{15 \cdot 5 !} t^{5}+\frac{1}{30 \cdot 6 !} t^{6}+\frac{1}{90 \cdot 7 !} t^{7}-\frac{1}{900 \cdot 9 !} t^{9}\right)\right] e^{-x t} d t .
\end{aligned}
$$

The proof will be done if we show that

$$
\begin{aligned}
p(t)=e^{t}\left(\frac{t^{3}}{12}+\frac{t}{15}-\right. & \left.\frac{1}{3}\right)+\frac{1}{3}+\frac{4}{15} t+\frac{3}{10} t^{2}+\frac{2}{15 \cdot 3 !} t^{3}+\frac{1}{15 \cdot 4 !} t^{4}+ \\
& +\frac{1}{15 \cdot 5 !} t^{5}+\frac{1}{30 \cdot 6 !} t^{6}+\frac{1}{90 \cdot 7 !} t^{7}-\frac{1}{900 \cdot 9 !} t^{9}>0
\end{aligned}
$$

for $t>0$. There are two cases:

a) $0<t \leqslant 2$,

в) $2<t$. 
Consider the case $\alpha$ ). It is easy to see that

$$
\frac{1}{90 \cdot 7 !} t^{7}-\frac{1}{900 \cdot 9 !} t^{9} \geqslant \frac{1}{90 \cdot 7 !} t^{7}\left(1-\frac{4}{720}\right)>0
$$

for $0<t \leqslant 2$. The proof of the case $\alpha$ ) will be done if we prove

$$
r(t)=e^{t}\left(\frac{t^{3}}{12}+\frac{t}{15}-\frac{1}{3}\right)+\frac{1}{3}+\frac{4}{15} t+\frac{3}{10} t^{2}>0
$$

for $0<t \leqslant 2$.

Straightforward computation gives:

$$
\begin{gathered}
r^{\prime}(t)=e^{t}\left(\frac{t^{3}}{12}+\frac{t^{2}}{4}+\frac{t}{15}-\frac{4}{15}\right)+\frac{4}{15}+\frac{3}{5} t, \\
r^{\prime \prime}(t)=e^{t}\left(\frac{t^{3}}{12}+\frac{t^{2}}{2}+\frac{17 t}{30}-\frac{1}{5}\right)+\frac{3}{5},
\end{gathered}
$$

and

$$
r^{\prime \prime \prime}(t)=e^{t}\left(\frac{t^{3}}{12}+\frac{3 t^{2}}{4}+\frac{47 t}{30}+\frac{11}{30}\right) .
$$

From $r^{\prime \prime \prime}(t)>0, r^{\prime \prime}(0)=2 / 5>0, r^{\prime}(0)=0$ we obtain $r(t)>0$ for $0<t \leqslant 2$.

Now consider the case $\beta$ ). For $t>2$, it is easy to see that

$$
\frac{t^{3}}{12}+\frac{t}{15}-\frac{1}{3}>\frac{1}{2}>0
$$

Using the elementary inequality, get

$$
e^{t}>1+t+\frac{t^{2}}{2}+\frac{t^{3}}{6}+\frac{t^{4}}{4 !}+\frac{t^{5}}{5 !}+\frac{t^{6}}{6 !}
$$

The proof of the case $\beta$ ) will be done if we prove that

$$
\begin{aligned}
q(t)=\left(1+t+\frac{t^{2}}{2}+\frac{t^{3}}{6}+\frac{t^{4}}{4 !}+\frac{t^{5}}{5 !}+\frac{t^{6}}{6 !}\right) \cdot\left(\frac{t^{3}}{12}+\frac{t}{15}-\frac{1}{3}\right)+ \\
+\frac{1}{3}+\frac{4}{15} t+\frac{3}{10} t^{2}+\frac{2}{15 \cdot 3 !} t^{3}+\frac{1}{15 \cdot 4 !} t^{4}+\frac{1}{15 \cdot 5 !} t^{5}+\frac{1}{30 \cdot 6 !} t^{6}+ \\
+\frac{1}{90 \cdot 7 !} t^{7}-\frac{1}{900 \cdot 9 !} t^{9}>0
\end{aligned}
$$

for $t>2$. 
By direct computation, we obtain that $q(t)=\frac{37799 \cdot t^{9}}{326592000}+\frac{t^{8}}{1440}+\frac{809 \cdot t^{7}}{226800}+\frac{101 \cdot t^{6}}{7200}+\frac{19 \cdot t^{5}}{450}+\frac{t^{4}}{12}+\frac{t^{3}}{12}+\frac{t^{2}}{5}>0$ this completes the proof.

Competing interests. The author declares that he has no competing interests.

Author's contributions. Author has approved the final manuscript.

Acknowledgment. The author would like to thank Professor Ondrušová, dean of FPT TnUAD, Slovakia, for his kind grant support. The work was supported by VEGA grants No. 1/0589/17, No. 1/0649/17, No. 1/0185/19, No. $1 / 0348 / 20$, No. 1/0026/20 and by Kega grant No. 007 TnUAD-4/2017, No. 002 TnUAD-4/2019.

\section{References}

[1] B. -N. Guo, J. -L. Zhao and F. Qi, A completely monotonic function involving the tri- and tetra-gamma functions, Math. Slovaca 63 (2013), no. 3, vol. 469478. DOI: https://doi.org/10.2478/s12175-013-0109-2.

[2] B. -N. Guo and F. Qi, On the degree of the weighted geometric mean as a complete Bernstein function, Afr. Mat. 26, 2015, no. 7, pp. 1253-1262. DOI: https://doi.org/10.1007/s13370-014-0279-2.

[3] L. Matejička, A Solution to Qi's Conjecture on a Double Inequality for a Function Involving the Tri- and Tetra-Gamma Functions, Mathematics, 2019, no. 7(11), vol. 1098. DOI: https://doi .org/10.3390/math7111098.

[4] F. Qi and R. P. Agarwal, On complete monotonicity for several classes of functions related to ratios of gamma functions, J. Inequal. Appl. 2019, vol. 36, 2019. DOI: https://doi.org/10.1186/s13660-019-1976-z.

[5] R. L. Schilling, R. Song and Z. Vondraček, Bernstein Functions: Theory and Applications, 2nd ed., de Gruyter Studies in Mathematics 37, Walter de Gruyter, Berlin, Germany, 2012.

DOI: https://doi.org/10.1515/9783110269338.

[6] D. V. Widder, The Laplace Transform, Princeton University Press, Princeton, 1946.

Received March 2, 2020.

In revised form, June 27, 2020.

Accepted July 1, 2020.

Published online July 11, 2020. 
Ladislav Matejička

Faculty of Industrial Technologies in Púchov

Trenčín University of Alexander Dubček in Trenčín

I. Krasku 491/30, 02001 Púchov, Slovakia

E-mail: ladislav.matejicka@tnuni.sk 